\title{
Advancing an Age-Friendly NYC
}

\section{Jo Ivey Boufford}

Published online: 13 June 2017

(C) The New York Academy of Medicine 2017

In 2006, the World Health Organization (WHO) launched the Global Age-friendly Cities project in recognition of the converging trends of urbanization and population aging. The leaders of the initiative asked 35 cities to lead discussions with their older residents to explore the strengths and challenges of aging in cities. The information gathered through this research, with the help of The New York Academy of Medicine, was used to develop a guide for global age-friendly cities.

Beginning in 2007, Mayor Michael Bloomberg, City Council Speaker Christine Quinn, and the Academy launched Age-friendly New York City with its first undertaking being a comprehensive assessment of the city's age-friendliness across the WHO's eight domains of an age-friendly city: The domains are (1) outdoor spaces and buildings, (2) transportation, (3) housing, (4) social participation, (5) respect and social inclusion, (6) civic participation and employment, (7) communication and information, and (8) community support and health services.

The assessment included guided conversations with more than 1500 older adults across the city in six languages, roundtable discussions with hundreds of professionals, a literature review, and extensive mapping. In the fall of 2008, the Academy released the findings of the assessment process in "Toward an Age-friendly City: A Findings Report.”

J. I. Boufford $(\bowtie)$

New York Academy of Medicine, New York, NY, USA e-mail: jboufford@nyam.org
In response to the findings of the community assessment, the Office of the Mayor and the New York City Council asked all city agencies to consider how they could improve the way they integrate and serve older adults through their work. Out of this review, in 2009, the city announced 59 initiatives to improve the quality of life of older adults, which are outlined in "Agefriendly NYC: Enhancing Our City's Livability for Older New Yorkers." Some of the resulting improvements include a reduction in senior pedestrian fatalities by $16 \%$, increased walkability through the addition of thousands of new benches, more than 3000 redesigned bus shelters, and new recreational and cultural programming for older people. The mayor Bill de Blasio's office is currently in the process of developing a new set of commitments to build upon the successes of the first phase of implementation and respond to emerging needs. Age-friendly NYC is an initiative of OneNYC, the city's strategic plan for growth, sustainability, resilience and equity.

Appointed by the mayor and staffed by the Academy, the Commission for an Age-friendly NYC is composed of civic leaders from across sectors and disciplines, working to develop the overall strategy for Agefriendly NYC and to engage private organizations in changing the culture of New York City to become more inclusive of older people. Convened for the first time in 2010 and reseated in 2015, the Age-friendly NYC Commission has helped New York City become a global leader in the age-friendly city movement through an array of innovative pilot projects, many of which have been replicated or adapted in other parts of the world. 
Products include the Cultural Arts Guide for Seniors, Age-friendly College Link-a database of educational opportunities for older people, and age-friendly tools for neighborhoods, small businesses, architects, building owners, librarians, and urban planners. Through 2018, the Commission is working to address priorities including housing, public safety, primary care, financial wellness, and media, arts, and culture.

To help communities become more inclusive of people of all ages, the Academy will pilot a new small grant program and will continue to expand and enrich our agefriendly neighborhood initiatives in partnership with local leaders and stakeholders.

For professionals, the Academy is launching a Healthy Aging Section of the Academy Fellows to improve the health, well-being, and engagement of older people in cities through inter-professional communication and networks; community/public advocacy; leadership development; and education, research, and policy involvement. This Fellows section will bring together physicians, nurses, social workers, dentists, pharmacists, nutritionists, and others, to work collaboratively with Age-friendly NYC.

Through these activities and many others, we will also continue to address critical, cross-cutting issues that affect older New Yorkers-social justice and equity, intergenerational communication, and rapidly changing technologies - as part of our sweeping effort to make NYC a safer, healthier, and happier place to age.

All of our findings from the planning and implementation of Age-friendly NYC are available to those seeking to transform their cities to be more age friendly. We have consulted with representatives from over 60 cities worldwide, and in 2013, Age-friendly NYC was awarded "Best Existing Age-friendly Initiative in the World" by the International Federation on Ageing. We welcome your ideas and look forward to learning about your strategies to make cities more age friendly. 